\title{
Physiological Interactions of Phaseolus vulgaris L. with Telfairia Mosaic Virus
}

\section{AAJ Mofunanya*, EA Effa, BA Ngele, FA Akomaye and AO Damian}

Department of Botany, Faculty of Biological Sciences, University of Calabar, Cross River State, Nigeria

*Corresponding Author: AAJ Mofunanya, Department of Botany, Faculty of Biological Sciences, University of Calabar, Cross River State, Nigeria.
Received: May 12, 2021

Published: May 26, 2021

(C) All rights are reserved by AAJ Mofunanya., et al.

\section{Abstract}

The study was conducted to investigate the physiological outcome of interactions of Phaseolus vulgaris L. with Telfairia mosaic virus (TeMV). Seeds of $P$. vulgaris used in this study were obtained from a farm where the plants were monitored on the field for virus symptoms expression. The seeds were sown, on germination inoculated with the virus at the two leaf stage and allowed to stay for symptom expression. Relative water content, leaf nitrogen content, photosynthetic pigments and enzymes activities were determined at different stages of growth to quantify host virus interactions physiologically. Due to virus infection, some physiological parameters like photosynthetic pigments (chlorophyll $a, b$ and carotenoids), relative water content (RWC), leaf nitrogen content were drastically reduced while all enzymes activity increased significantly. Interaction of $P$. vulgaris with TeMV led to decrease in RWC and leaf nitrogen content. Percentage decrease in RWC of $40.1 \%$ at 12 weeks after inoculation (WAI)and 57.6\% for leaf nitrogen at 2 WAI was found. Telfairia mosaic virus interaction caused reduction in leaf chlorophyll a content of 53.6\%, chlorophyll $b(32.9 \%)$, chlorophyll $\mathrm{a}+\mathrm{b}(46.6 \%)$, ratio of chlorophyll $a / b(30.8 \%)$ and carotenoids $(50.0 \%)$. The virus interactions engendered increase in the activities of peroxidase (POD), polyphenol oxidase (PPO), glucose-6-phosphate dehydrogenase (G6PdH), 6-phosphogluconate dehydrogenase (6PGdH) enzymes of 57.0\%, 64.9\%, 90.4\%, 99.1\% respectively at 8 WAI. Interactions brought about changes in host physiology with variations in quantity of physiological components affecting whole plant functioning.

Keywords: Enzymes Activities; Interaction; Photosynthetic Pigments; Phaseolus vulgaris

\section{Introduction}

Plant-virus interaction cause significant alterations in host cellular metabolism. These physiological changes are crucial in sustaining plant life and health essential in plant performance and productivity which are of benefit to man. Human population increase has placed a huge demand on food production. To accomplish this, among other things, crop growers constantly monitor the crop's health in the field since stress conditions affect photosynthetic activity, which is closely related to yield. There are sev- eral variables related to crop health, but our interest is on virus effect. This is due to the high correlation found between chlorophyll content and health of plants [1]. Basic physiological processes commonly affected in host-virus interactions included photosynthesis, respiration, growth etc. [2]. A decrease in photosynthesis is manifested by reduction in chlorophyll and other plant pigments. Measurement of photosynthetic pigments, relative water content and enzyme activities which are essential indicators of physiological status of the plant will provide the basis to understand the fate 
of existing physiological changes in P. vulgaris upon interaction with TeMV. The present study investigated the impact of $P$. vulgaris interaction with TeMV on basic physiological parameters linked to plant health and performance.

\section{Materials and Methods}

Relative water content determination

The relative water content of TeMV-inoculated and control leaves of $P$. vulgaris were determined by the method of [3]. Ten leaf pieces ( $2 \mathrm{~cm}$ diameter) were cut from these leaves and weighed immediately to obtain their fresh weight (FW). Turgid weight (TW) was determined by weighing the leaf segments after $24 \mathrm{~h}$ of immersion in distilled water in a sealed flask at room temperature. Dry weight (DW) was determined by weighing leaf segments after $48 \mathrm{~h}$ at $70^{\circ} \mathrm{C}$ in an oven. The relative water content of leaves was calculated and expressed as a percentage.

\section{Leaf-N-status estimation}

Nitrogen is inherent molecule in chlorophyll pigment. Leaf samples were obtained at 2, 4, 6, 8, 10 and 12 WAI from TeMV-inoculated and healthy $P$. vulgaris. Leaf sample of $20 \mathrm{~g}$ each was oven-dried, pulverized and analyzed for percentage leaf $\mathrm{N}$ content determination using standard Kjeldahl techniques.

\section{Chlorophyll and carotenoids estimation}

Chlorophyll a, chlorophyll $\mathrm{b}$ and carotenoids were estimated by obtaining $25 \mathrm{mg}$ leaf samples from TeMV-infected and healthy $P$. vulgaris based on the method of [4] at various stages of growth. The leaf samples were homogenized using mortar and pestle in the dark with $2 \mathrm{ml}$ of aqueous acetone (80\%) and centrifuged at $5000 \mathrm{rpm}$ for 10 minutes at $5^{\circ} \mathrm{C}$. Pigments were estimation by taking absorbance readings at specific absorption coefficients with a spectrophotometer (Model 722S, England). The leaf chlorophyll a, $\mathrm{b}$ and carotenoids were expressed in $\mathrm{mg}^{-1} \mathrm{FW}$.

\section{Enzyme extraction}

Enzyme extraction buffer comprised of $50 \mathrm{mM}$ mixed monobasic potassium phosphate salt $\left(\mathrm{KH}_{2} \mathrm{PO}_{4}\right), 50 \mathrm{nM}$ dibasic potassium phosphate $\left(\mathrm{K}_{2} \mathrm{HPO}_{4}\right)$, to this was added $4 \mathrm{~g}$ of polyvinyl polypyrrolidone (PVPP) a phenol absorbent. The mixture was thoroughly mixed with the aid of a magnetic stirrer and adjusted to final $\mathrm{pH}$ 7.0. Enzyme extraction was carried out at $4^{\circ} \mathrm{C}$ with $0.2 \mathrm{~g}$ of TeMV inoculated and control leaf tissues of $P$. vulgaris harvested ran- domly from experimental plots at different periods of growth and homogenized in pre-chilled mortar and pestle in $10 \mathrm{ml}$ extraction buffer. The homogenate filtered through cheese cloth and the filtrate centrifuged at 4,000 rpm for 4 minutes. The supernatants for inoculated and control samples were stored in an ice chamber and used as crude enzyme sources in assaying POD and PPO.

Enzyme assay

Enzyme assay was carried out using a mixture of $50 \mathrm{mM}$ mixed monobasic potassium phosphate salt $\left(\mathrm{KH}_{2} \mathrm{PO}_{4}\right), 50 \mathrm{nM}$ dibasic potassium phosphate $\left(\mathrm{K}_{2} \mathrm{HPO}_{4}\right)$ and $\mathrm{pH}$ adjusted to 7.0. Readings were obtained at appropriate wavelength for each enzyme with the aid of a spectrophotometer (Model 722S, England).

\section{Peroxidase assay (EC.1.11.17.7)}

In a cuvette containing $2 \mathrm{ml}$ assay buffer was added $0.1 \mathrm{ml}$ of 10 $\mathrm{ml}$ guaiacol and $0.1 \mathrm{ml}$ enzyme preparation. The reaction was initiated with the addition of $0.1 \mathrm{ml}$ of $10 \mathrm{mM} \mathrm{H}_{2} \mathrm{O}_{2}$, making up the final assay volume of $2.3 \mathrm{ml}$. Absorbance readings were taken at $436 \mathrm{~nm}$ at 1 minute spectrophotometrically using the assay buffer as blank. The expressed POD activity was calculated using an extinction coefficient $6.39 \mathrm{mMcm}^{-1}$ for guaiacol dehydrogenation product.

Polyphenol oxidase assay (EC.1.14.18.1)

To $2 \mathrm{ml}$ of assay buffer in a cuvette was added $0.1 \mathrm{ml}$ of $10 \mathrm{mM}$ dihydroxyphenylalamine (DOPA) and $0.1 \mathrm{ml}$ enzyme preparation. The reaction was started by adding $0.1 \mathrm{ml}$ of $10 \mathrm{mM} \mathrm{H}_{2} \mathrm{O}_{2}$ in a final volume of $2.3 \mathrm{ml}$. The absorbance was taken at 1 minute spectrophotometrically at $470 \mathrm{~nm}$ [5]. The activity of PPO expressed was calculated using an extinction coefficient of $1433 \mathrm{nMcm}^{-1}$.

Glucose 6 phosphate dehydrogenase (G6PdH: EC1.1.1.44) and 6 phosphogluconic acid dehydrogenase (6PGdH: EC 1.1.1.49) assay

These enzymes activities were conducted spectrophotometrically at $3^{\circ} \mathrm{C}$ following the reduction of NADP at $340 \mathrm{~nm}$. The assay mixtures consisted of $100 \mathrm{ml}$ triethanolamine hydrochloride$\mathrm{NaOH}, 10 \mathrm{ml} \mathrm{MgCl}_{2}, 10 \mathrm{ml} \mathrm{NADP}, 10 \mathrm{ml}$ 6-phophogluconate or glucose 6-phosphate and $5 \mathrm{ml}$ of crude enzyme extract at $\mathrm{pH}$ 7.5. To $2 \mathrm{ml}$ assay buffer contained in a cuvette was added $0.1 \mathrm{ml}$ of 0.8 $\mathrm{mM}$ 6PGdH or $0.1 \mathrm{ml}$ of $0.83 \mathrm{mM} \mathrm{MgCl}_{2}$, NADP and $0.1 \mathrm{ml}$ crude enzyme extract added to start the reaction in a final volume of 2.4 
$\mathrm{ml}$ and readings taken spectrophotometrically at $430 \mathrm{~nm}$ for inoculated and healthy leaves samples of $P$. vulgaris in $\mathrm{Ug}^{-1}$ fresh weight for $4 \mathrm{~min}$. All G6PdH activities were corrected for the possible complicating effect of 6PGdH on the G6PdH assay [6].

\section{Statistical analysis}

The independent t-Test statistics was used to analyze the significant difference between inoculated and control plants. Data were also expressed as percentage difference and differences between mean values were determined at $5 \%$ probability.

\section{Results}

Relative water content and leaf nitrogen content of $P$. vulgaris were severely altered by TeMV infection. Infection led to decrease in RWC and leaf nitrogen contents of inoculated plants when compared to the controls. At $10 \mathrm{WAI}$, mean decrease in RWC of 48.13 \pm 0.03 as against $80.43 \pm 0.10$. Results revealed highest mean decrease in leaf nitrogen of $25.51 \pm 0.02$ and lowest of $23.07 \pm 0.03$ for infected plants compared to the control values of $60.35 \pm 0.03$ and $40.38 \pm 0.01$ at 2 WAI and at 12 WAI. Leaf nitrogen decreased with prolonged period of growth (Figure $1 \mathrm{~A}$ and $1 \mathrm{~B}$ ).

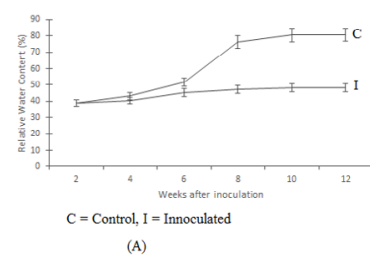

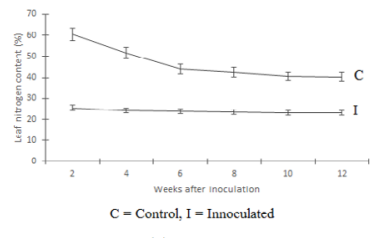

(B)
Figure 1: Interaction of TeMV on Relative water $(1 \mathrm{~A})$ content and leaf nitrogen (1B) of Phaseolus vulgaris.

Interaction of TeMV with photosynthetic pigments of $P$. vulgaris resulted in drastic reduction in contents at all periods of growth compared to control plants (Figure 2A-2E). Photosynthetic pigments of both inoculated and control plants showed a trend of increase with progressive periods of growth. Statistically, results revealed decrease in chlorophyll $a, b$, chlorophyll $a+b$, ratio of chlorophyll $a / b$ and carotenoids at 12 WAI of $2.12 \pm 0.01,1.55 \pm$ $0.02,3.67 \pm 0.01,1.37 \pm 0.01$ and $0.53 \pm 0.00 \mathrm{mg} / \mathrm{g}$ FW compared to the control plants $4.57 \pm 0.01,1.78 \pm 0.01 \mathrm{mg} / \mathrm{g}$ FW. Corresponding values for the control were $4.57 \pm 0.01,2.31 \pm 0.02,6.88 \pm 0.01$, $1.98 \pm 0.01$ and $1.06 \pm 0.01 \mathrm{mg} / \mathrm{g} \mathrm{FW}$.

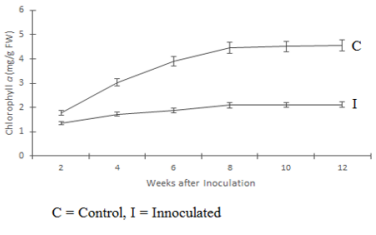

(A)

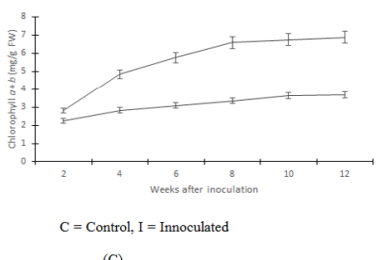

(C)

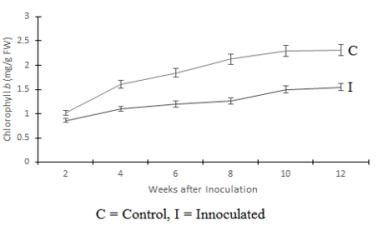

(B)
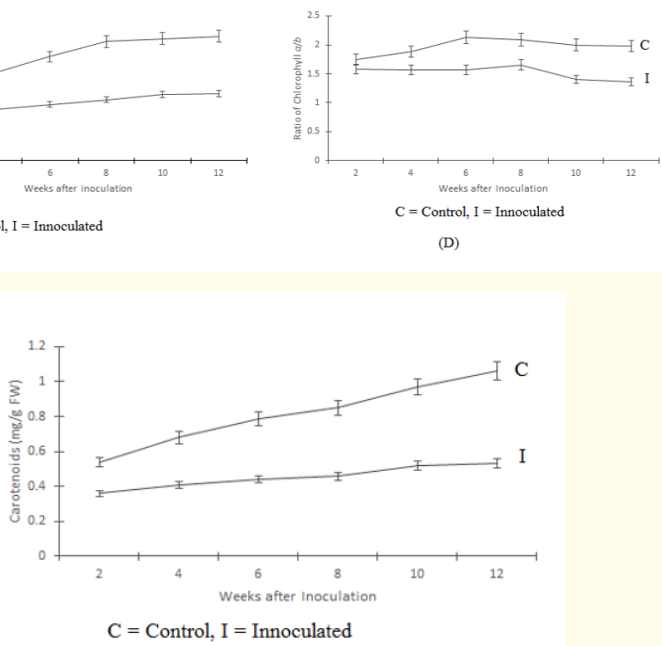

(E)
Figure 2: Interaction of Telfairia mosaic virus with photosynthetic pigments of Phaseolus vulgaris.

Activity of enzymes of the glycolytic and the pentose phosphate pathways were significantly altered by TeMV. Interaction of the virus with all enzymes revealed significant $(P=0.05)$ increase in activity at all periods of growth compared to the control. In all enzymes, interactions depicted significant increase from initial period of 2 WAI to 12 WAI. Increase in POD, PPO, G6PdH and 6PGdH activity in inoculated plants when compared to control plants at 8 WAI were $4895.15 \pm 0.02$ and $3117.06 \pm 0.00 \mathrm{u} / \mathrm{min} / \mathrm{mg}$ of protein, $21.12 \pm$ 0.02 and $12.81 \pm 0.01 \mathrm{u} / \mathrm{min} / \mathrm{mg}$ of protein, $3.39 \pm 0.01$ and 1.78 $\pm 0.01 \mu \mathrm{mol}$. NADPH formed $/ \mathrm{min}$ of protein, $3.80 \pm 0.01$ and 1.89 $\pm 0.02 \mu \mathrm{mol}$. NADPH formed/min of protein respectively (Figure 3A-3D). 

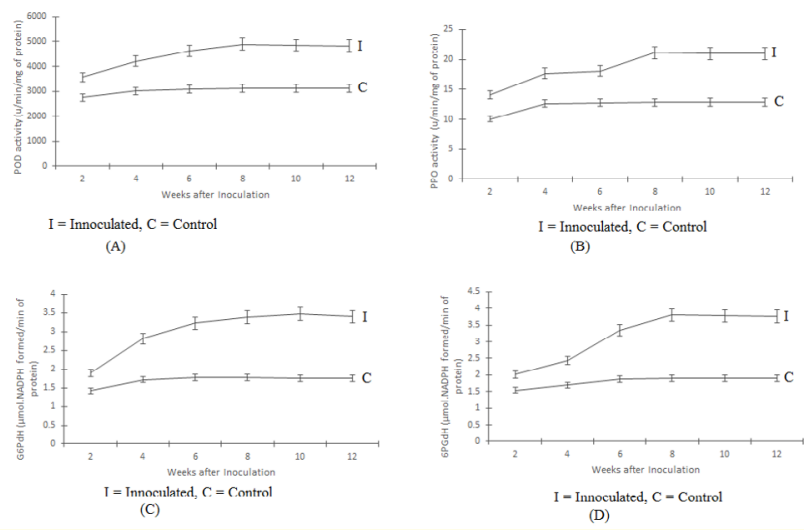

Figure 3: Interaction of Telfairia mosaic virus with peroxidase (A), polyphenol oxidase (B), glucose-6-phosphate dehydrogenase (C) and 6-phosphogluconic acid dehydrogenase (D) activity of Phaseolus vulgaris.

\section{Discussion}

The study elucidated interactions of $P$. vulgaris with TeMV in order to ascertain its effects on host plant physiology. Reduction in RWC in leaves of $P$. vulgaris due to interaction with TeMV in this study is in agreement with previous report of lower water content in virus-infected leaves than in corresponding healthy tissues [2]. Relative water content in leaves of pepper plants infected by TMV decreased significantly [7], pepper-tobamo virus interaction led to loss of turgidity in infected leaves [8]. When leaves lose water, physiological processes are altered. Physiological processes are powered by water and water reduction decreased their efficiencies. Photosynthesis is highly sensitive to water, thus, even slight loss of water content in leaf decreased the efficiency of the process. Relative water content is an indicator of water status of plants important in maintaining cell turgidity, structure and growth, transporting nutrients and organic compounds throughout the plant, serving as a raw material for various chemical processes, photosynthesis, respiration, transpiration, buffering the plant against wide temperature fluctuations. Relative water content is a sensitive indicator to plant growth and yield. Reduction in RWC may be due to abrasive or damage to leaves tissues during virus inoculation with alterations in physiological processes.
Leaf nitrogen content was significantly lower at all stages of growth in P. vulgaris as a result of interaction with TeMV. Nitrogen is a basic component of protein, enzymes, nucleic acids, amino acids and chlorophyll. Nitrogen is required for the synthesis of energy compounds; NADH, ATP, carbohydrates and lipids. Nitrogen is a vital determinant of growth and has the potential of improving the quality and yield of crops. Reduction in leaf $\mathrm{N}$ may affect photosynthetic capacity of inoculated plants since leaf $\mathrm{N}$ is an integral part of the chlorophyll molecule with grave effects on growth and yield. Nitrogen is an imperative factor in plant growth and governs a major constituent of chlorophyll and photosynthetic activity [9].

Some physiological changes were observed due to interaction of P. vulgaris with TeMV. Reduction in chlorophyll $a$, $b$, total chlorophyll and the ratio of chlorophyll $a / b$ which occurred as a result of TeMV interaction are injurious to the physiological status of $P$. vulgaris. Reduction in chlorophyll contents have occurred in other host-virus interactions; [10] found lesser amount of chlorophyll a, chlorophyll b, total chlorophyll and carotenoids in susceptible cultivars of Tungro infected rice plant. [11] reported decrease in total chlorophyll, chlorophyll a and b in virus infected sunflower leaves. Chlorophyll is the green photosynthetic pigment in plants that has the capacity to transfer the radiant energy of sunlight into chemical energy of food in the process called photosynthesis which is basic for the physiological mechanisms of plants and for life on earth. Aside food production, chlorophylls are of immense importance to plants: Leaf chlorophyll concentration is an indicator of chloroplast content, photosynthetic mechanism and plant metabolism. Chlorophylls are the primary metabolites that give colour to leaves and fruits, specially, in the unripe stage. This green pigment can be used as indicators of plant health stress and nutritional deficiencies. Chlorophyll pigments are an indicator of $\mathrm{O}_{2}$ production and carbon sequestration. Decrease in chlorophyll orchestrated by TeMV interaction is an indication of altered physiological characteristic of $P$. vulgaris. This decrease is threatening because food production by plants remains its major function to meet the food needs of the populace worldwide. Plants achieve this fit with the aid of photosynthetic pigments. It provides the energy that drives virtually all ecosystems. Decrease in chlorophyll $a$ and $b$ in this study may be due to severe mosaic symptoms of TeMV, it may also be attributed to the fact that chlorophyll is synthesized in the chloroplast which is the site of replication for several viruses. When viruses replicate in chloroplasts, photosynthesis, a basic physiological process of 
plant is inhibited. There had been a strong drive on the commercial production of chlorophyll as a natural pigment used as indispensable components in the food industries, in pharmaceuticals, and in cosmetics [12,13], necessitating control of TeMV to maintain normal levels of chlorophyll.

Carotenoids content suffered reduction due to P. vulgaris-TeMV interactions. Reports of virus infection on plant pigments are found: [14] found decrease in chlorophyll $b$ and $a$ in cowpea (Vigna unguiculata) susceptible to Cowpea severe mosaic virus infection. [15] reported a reduction in total chlorophyll, chlorophyll $\mathrm{a}, \mathrm{b}$ and $\beta$-carotene in chilli plants infected with Cucumber mosaic virus. Multiplication of virus particles in the infected cells altered the biochemical compounds of cells that disrupt physiological processes which affect the growth and yield of infected plants. In plants, carotenoids play important roles in light harvesting, photosynthesis, photoprotection, pollinator attraction and phytohormone production, strigolactone synthesis, shoot branching and signaling [16]. Carotenoids signal the production of abscisic acid, which regulates plant growth, seed dormancy, embryo maturation and germination, cell division and elongation, floral growth, and stress responses [17]. Carotenoids reduction in this study may be linked to severe mosaic symptom characteristic of TeMV.

Peroxidase activity was higher in $P$. vulgaris interaction with TeMV in comparison to the control. Physiologically, interactions of $P$. vulgaris with TeMV led to the production of reactive oxygen species which has a damaging effect on the plant. To stay alive, cells of $P$. vulgaris evolved mechanisms for the synthesis of antioxidant among others, to ameliorate the danger posed by cellular oxidants. The enzymatic antioxidants studied were POD and PPO. Telfairia mosaic virus induced an increased oxidative stress, as the activity of antioxidant enzymes was higher in the inoculated samples than in the control. Increase in these enzymes corresponds to increase in rates of respiration. In many host virus combination where necrosis does not occur, there is a rise in respiration rate, which begin before symptoms appear and continue for a time as disease develops [2]. Peroxidase is the first enzyme to show changes in its activity under virus infection and is actively involved in the ROS mechanisms, and accumulation of which causes oxidative damage. Peroxidase catalyzes the final polymerization step of lignin synthesis. Therefore, higher activity of POD leads to lignification process which is considered as a resistance mechanism against pathogen attack. By way of oxidation of indole-3-acetic acid, upregulated peroxidases might also be responsible for growth reductions and malformations in virus-infected plants [18].

Polyphenol oxidase play a role in plant immunity, might also be involved in many physiological processes. Polyphenol oxidase might have a role in photosynthesis as an oxygen buffer or interacting with the Mehler-peroxidase reaction [19]. Elevated PPO activity was found in P. vulgaris interaction with TeMV. Polyphenol oxidase is an important enzyme in the initial stage of plant defense where membrane damage caused release of phenols. The enzyme catalyzes the oxidation of phenolics to free radicals that can react with biological molecules, creating an unfavourable environment for pathogen development [20]. Enzymes control biochemical reactions in cells. Any change in the activity of an enzyme would reflect the pattern of expression and corresponding metabolic events. Biochemically enzymes are tools used to study the induced responses of infected plants showing disease symptoms. Peroxidase and PPO are phenol oxidizing enzymes associated with diseases. Increased POD and PPO enzymes activity in this study was due to the high energy demand placed on P. vulgaris by TeMV, it may also be an indication of their participation in scavenging ROS. It was also found that increase in enzymes activity correlated with symptom severity thus, the higher the severity of symptoms, the higher enzymes activity.

Interaction of TeMV with enzymes of $P$. vulgaris led to enhanced activity of G6PdH and 6PGdH. Glucose-6-phosphate dehydrogenase and 6-phosphogluconate dehydrogenase are two important enzymes of the pentose phosphate pathway (PPP) involved in the production of NADPH and play an important role in plant development and stress responses. The PPP is a pathway of glucose metabolism in plants, and its main physiological function is in the generation of NADPH. This pathway also converts G6P into ribulose-5-phosphate (Ru5P), a precursor for the synthesis of nucleotides. The PPP meets the energy need of all organisms and it is an alternative respiratory pathway for energy production. Increase in the activities of G6PdH and 6PGdH in P. vulgaris - TeMV interaction suggest increase in respiration. Reduction in photosynthetic pigments correlated with increased G6PdH and 6PGdH activity. This finding agrees with earlier report of enhanced enzymes activity of G6PdH and 6PGdH in TeMV-infected A. viridis [21], accumulation of glucose-6-phosphate in Pepper mild mottle virus infected 
pepper [22]. Increase in respiration occasioned by increase in enzymes activities by $P$. vulgaris-TeMV interaction may be ascribed to increased metabolism, increased activation of the PPP [23]. Virus infection places a high energy demand to enable the infected plant cope with viral genome replication and coat protein synthesis and to compensate for the decrease in photosynthesis. Energy required for the plant metabolic processes is derived from ATP. The more ATP is utilized the more ADP is produced inciting respiration. Interaction with TeMV should be prevented to promote $P$. vulgaris performance for maximum productivity to meet the food need of the people.

\section{Conclusion}

The study revealed that physiological interactions of $P$. vulgaris with TeMV led to decrease in relative water content, percentage leaf nitrogen, chlorophyll a, Chlorophyll $b$ and carotenoids. Interactions however, enhanced POD, PPO, G6PdH and 6PGdH enzyme activities. Chlorophyll pigments are important indicators for measuring plant growth and yield. Decrease in its content directly affects plant health culminating in yield loses. The study revealed a gradual decrease in some physiological parameters with increase in others plant parameters occasioned by TeMV at different stages of $P$. vulgaris growth. Increase in enzyme activities was to complement low energy production due to decrease in chlorophyll.

\section{Conflict of Interest}

Authors have declared that there is no conflict of interest.

\section{Acknowledgement}

Authors are grateful to the Department of Botany for facilities used for this research.

\section{Bibliography}

1. Munoz-Huerta R F., et al. "A review of methods for sensing the nitrogen status in plants: advantages, disadvantages and recent advances". Sensor 13.8 (2013): 10823-10843.

2. Hull R. "Matthew's plant virology". London, Academic Press Incorporated (2002).

3. Efeoglu B., et al. "Physiological responses of three maize cultivars to drought stress and recovery". South African Journal of Botany 75 (2009): 34-42.
4. Lichthenthaler H K. "Chlorophylls and carotenoids: pigments of photosynthetic biomembranes". Methods in Enzymology 148 (1987): 350-382.

5. Kahn V. "Multiple effects of hydrogen peroxide on the activity of avocado polyphenol oxidase". Phytochemistry 22 (1983): 2155-2159.

6. Gosling PG and Ross JD. “Characterization of glucose-6-phosphate dehydrogenase and 6-phosphogluconic acid dehydrogenase from hazel cotyledons". Phytochemistry 18 (1979): 14411445.

7. Pazarlar S., et al. "The effects of Tobacco mosaic virus infection on growth and physiological parameters in some pepper varieties (Capsicum annuum L.)". Notulae Botanicae Horti Agrobotanici Cluj-Napoca 41.2 (2013): 427-433.

8. Rys M., et al. "Comparison of a compatible and an incompatible pepper-tobamovirus interaction by biochemical and noninvasive techniques: chlorophyll $a$ fluorescence, isothermal calorimetry and FT-Raman spectroscopy". Plant Physiology and Biochemistry 83 (2014): 267-278.

9. Nursu aidah H. "Growth and photosynthetic responses of long bean (Vigna unguiculata) and mung bean (Vigna radiata) response to fertilization". Journal of Animal Physiology 24 (2014): 573-578.

10. Jabeen A., et al. "Variation in chlorophyll and carotenoid contents in Tungro infected plants". Journal of Research Development 5.1 (2017): 1000153.

11. Papaiah S., et al. "Symptomlogical and biochemical studies on sunflower necrosis disease in sunflower plants in Rayalaseema region of Andhra Pradesh, India". Annals of Biological Research 3.1 (2012): 170-178.

12. Hosikian A., et al. "Chlorophyll extraction from microalgae: A review on the process engineering aspects". International Journal of Chemical Engineering (2010): 11.

13. Qaisar U., et al. "Commercial Applications of Plant Pigments". International Journal of Biotech Trends and Technology 9.3 (2019). 
14. Souza P F N., et al. "Photosynthetic and biochemical mechanisms of an EMS-mutagenized cowpea associated with its resistance to cowpea severe mosaic virus". Plant Cell Report 36 (2017): 234.

15. Rahman Md S., et al. "Effects of Cucumber mosaic virus on cellular components, host physiology and yield". Plant Tissue Culture and Biotechnology 29.2 (2019): 219-230.

16. Yoneyama K., et al. "Conversion of carlactone to carlactonic acid is a conserved function of MAX homologs in strigolactone biosynthesis". New Phytologist 218.4 (2018): 1522-1533.

17. Finkelstein R. "Ascisic acid synthesis and response". The Arabidopsis Book/American Society of Plant Biologists 11 (2013): e0166.

18. Riedle-Bauer M. "Role of reactive oxygen species and antioxidant enzymes in systemic virus infections of plants". Journal of Phytopathology 148 (2000): 297-302.

19. Taranto F., et al. "Polyphenol oxidases in crops: biochemical, physiological and genetic aspects". International Journal of Molecular Science 18 (2017): 377.

20. Araji S., et al. "Novel roles for the phlyphenol oxidase enzyme in secondary metabolism and the regulation of cell death in walnut". Plant Physiology (2014): 113.

21. Mofunanya A A J., et al. " Changes in some enzymes activities of Amaranthus viridis L. inoculated with Telfairia mosaic virus (TeMV)". Journal of Applied Life Sciences International 15.3 (2017): 1-11.

22. Janeczko A., et al. "Comparative studies of compatible and incompatible pepper-Tobamovirus interactions and the evaluation of effects of 24-epibrassinolide". Photosynthetica 56.3 (2018): 763-775.

23. Hull R. "Effects on plant metabolism". In: Comparative plant virology, $2^{\text {nd }}$ edition. Academic Press, Norwich (2009): 181-185.

\section{Volume 5 Issue 6 June 2021}

(C) All rights are reserved by AAJ Mofunanya., et al. 